\title{
A new strategy for membrane-based direct air capture
}

\author{
Shigenori Fujikawa $\mathbb{D}^{1,2,3} \cdot$ Roman Selyanchyn $\mathbb{D}^{1} \cdot$ Toyoki Kunitake ${ }^{1,2}$
}

Received: 23 July 2020 / Revised: 12 September 2020 / Accepted: 13 September 2020 / Published online: 15 October 2020

(c) The Author(s) 2020. This article is published with open access, corrected publication 2020

\begin{abstract}
Direct $\mathrm{CO}_{2}$ capture from the air, so-called direct air capture (DAC), has become inevitable to reduce the concentration of $\mathrm{CO}_{2}$ in the atmosphere. Current DAC technologies consider only sorbent-based systems. Recently, there have been reports that show ultrahigh $\mathrm{CO}_{2}$ permeances in gas separation membranes and thus membrane separation could be a potential new technology for DAC in addition to sorbent-based $\mathrm{CO}_{2}$ capture. The simulation of chemical processes has been well established and is commonly used for the development and performance assessment of industrial chemical processes. These simulations offer a credible assessment of the feasibility of membrane-based DAC (m-DAC). In this paper, we discuss the potential of m-DAC considering the state-of-the-art performance of organic polymer membranes. The multistage membrane separation process was employed in process simulation to estimate the energy requirements for m-DAC. Based on the analysis, we propose the target membrane separation performance required for m-DAC with competitive energy expenses. Finally, we discuss the direction of future membrane development for DAC.
\end{abstract}

\section{Introduction}

Carbon dioxide emissions into the atmosphere are the main reason for climate change. Drastic reductions in $\mathrm{CO}_{2}$ emissions into the atmosphere are unavoidable to meet the $1.5^{\circ} \mathrm{C}$ scenario recommended by the Intergovernmental Panel on Climate Change [1]. Unfortunately, it has become apparent that the $1.5^{\circ} \mathrm{C}$ scenario cannot be achieved simply by reducing $\mathrm{CO}_{2}$ emissions to the atmosphere [2-4]. This has led to the need for a more progressive approach, called negative emission technologies. These technologies include direct $\mathrm{CO}_{2}$ capture (direct air capture (DAC)) from ambient air by chem- or physisorption processes and other approaches, such as the use of bioderived energy combined with carbon capture and storage (BECCS), enhanced weathering of minerals, afforestation, and reforestation [5-8]. Among

Shigenori Fujikawa

fujikawa.shigenori.137@m.kyushu-u.ac.jp

1 International Institute for Carbon-Neutral Energy Research (WPII2CNER), Kyushu University, 744 Motooka, Nishi-ku, Fukuoka 819-0395, Japan

2 NanoMembrane Technologies, Inc., 4-1, Kyudai-Shimachi, NishiKu, Fukuoka 819-0388, Japan

3 Department of Chemistry and Biochemistry, Center for Molecular Systems (CMS), Kyushu University, 744 Motooka, Nishiku, Fukuoka 819-0395, Japan these technologies, DAC has a removal capacity comparable to that of BECCS ( $\sim 3.3 \mathrm{Gt}-\mathrm{C} /$ year), which requires a large amount of land and water [9-11]. While the potential of DAC based on sorption technologies has been proven, it requires considerable energy to desorb $\mathrm{CO}_{2}$ from the sorbents $[12,13]$.

Membrane separation is also one of the major technologies for capturing $\mathrm{CO}_{2}$. Compared to other conventional capture methods, $\mathrm{CO}_{2}$ capture by permselective membranes has advantages because of its smaller footprint and simpler setup and operation. However, large-scale membrane separation is still in its infancy, with only a few pilot plants operating at $\mathrm{CO}_{2}$ mass emission points, such as coal-fired power plants that emit flue gases containing $10-15 \% \mathrm{CO}_{2}$ [14]. Merkel et al. concluded that improved gas permeance in membranes is more critical for reducing capture cost than enhanced selectivity [15]. Compared to concentrated $\mathrm{CO}_{2}$ emission sources, the partial pressure of $\mathrm{CO}_{2}$ in the air is only $40 \mathrm{~Pa}$, which is considered too small to pass $\mathrm{CO}_{2}$ through membranes effectively. Keith et al. also mentioned that DAC by membranes seems implausible, given the relatively low molecular fluxes through membranes [16]. Based on these considerations, membrane-based DAC (mDAC) has never been considered [6].

Recently, many efforts have been devoted to the development of polymeric materials with high $\mathrm{CO}_{2}$ permeance. For example, Yoo et al. reported defect-free Teflon-based membranes possessing a $\mathrm{CO}_{2}$ permeance of $\sim 31,500 \mathrm{GPU}$ 


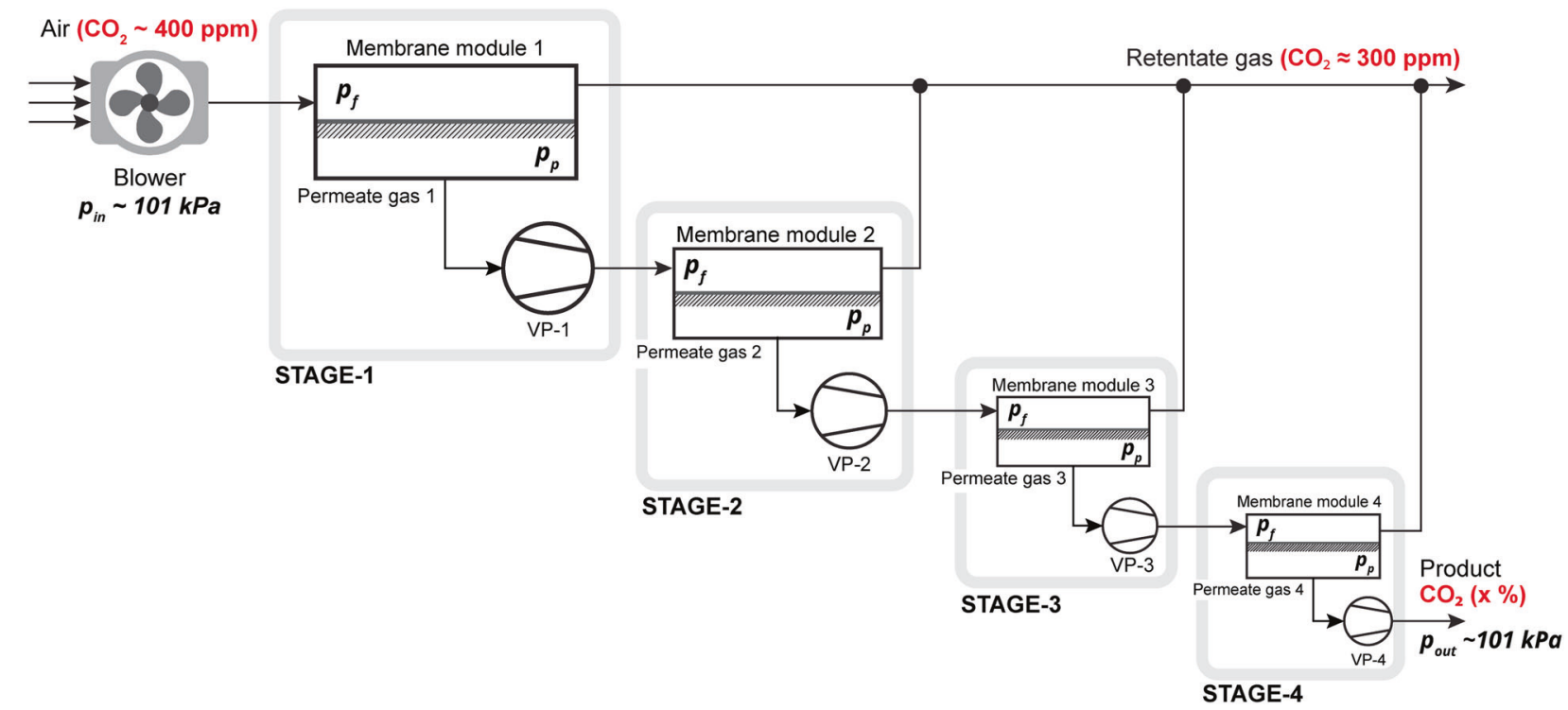

Fig. 1 Simplified scheme of the multistage membrane separation model used for process simulation in Aspen Plus (process constraints: retentate $\mathrm{CO}_{2}=300 \mathrm{ppm}$ at every separation stage, feed pressure $p_{f} \sim$

(GPU: gas permeance unit, 1 GPU $=7.5 \times 10^{-12} \mathrm{~m}^{3}(\mathrm{STP})$ $\mathrm{m}^{-2} \mathrm{~s}^{-1} \mathrm{~Pa}^{-1}$, STP: standard temperature and pressure) with a $\mathrm{CO}_{2} / \mathrm{N}_{2}$ selectivity of 3.3 [17]. We have also reported freestanding siloxane nanomembranes with high $\mathrm{CO}_{2}$ permeances exceeding 40,000 GPU [18]. Such membranes with ultrahigh gas permeance and selectivity would have the potential to capture $\mathrm{CO}_{2}$ efficiently, even from the air, since the gas permeance resistance through the membranes is quite small. Based on recent achievements in the membrane field, it is meaningful to evaluate the potential of membrane separation as an alternative DAC process. Analysis of membrane separation using process simulation has been well established based on chemical engineering aspects. This process analysis based on computational chemical engineering can assess the performance and feasibility of m-DAC from a realistic standpoint.

In this paper, we explored the potential of m-DAC based on process simulation with consideration of the state-of-theart $\mathrm{CO}_{2}$ separation membrane performance. The future direction of membrane development for DAC is discussed.

\section{Preliminary feasibility evaluation of $\mathbf{m}$-DAC}

For the initial investigation of the feasibility of m-DAC, we assumed a membrane with a permeance of 40,000 GPU and selectivity of 70, for which performances have been separately achieved in different membranes [18, 19]. Aspen Plus V11 (AspenTech, USA) flowsheeting software with the Peng-Robinson state equation thermodynamic model was used. The membrane separation process was modeled using the third-party unit operation MEMSIC, acquired from the
$101 \mathrm{kPa}(\sim 1 \mathrm{~atm})$, permeate pressure $p_{p}=5 \mathrm{kPa}$, pressure ratio, $\varphi \approx 20$; $\mathrm{CO}_{2} / X$ selectivity of the membranes was considered equal to 70 , where $X$ identifies other components of air $\left(\mathrm{N}_{2}, \mathrm{O}_{2}, \mathrm{Ar}\right)$

University of Lorraine [20]. The following conditions were used for the process simulation:

(1) The $\mathrm{CO}_{2}$ concentration of the retentate gas should be $\sim 300 \mathrm{ppm}$, which is the level in the preindustrial period.

(2) The pressures of the feed and permeate sides are $101.3 \mathrm{kPa}$ (atmospheric pressure) and $5 \mathrm{kPa}$, respectively.

(3) Multistage separation with four membrane separation units connected in series was considered (Fig. 1).

(4) The process is driven by vacuum pumps, which are units of the process that require energy.

(5) The outcomes of the energy requirements and required membrane area are normalized on the mass of $\mathrm{CO}_{2}$ in the product stream.

The results of the process simulation are summarized in Table 1. The relevant $\mathrm{CO}_{2}$ concentration of $>10 \%$ in the permeate is reached by three- and four-stage separations, while single- or two-stage separation remains below $3 \% \mathrm{CO}_{2}$. Concerning the membrane area, the required membrane area for four-stage separation is only $\sim 3.2 \mathrm{~m}^{2} / \mathrm{kg} \mathrm{CO} /$ day as a flat sheet. This membrane area can be assembled into the membrane module with a volume of less than $0.01 \mathrm{~m}^{3}$ (for $1 \mathrm{~kg}-\mathrm{CO}_{2}$ capture per day) estimated from the empirical membrane surface-tovolume ratio for plate-and-frame modules $\left(\sim 100-150 \mathrm{ft}^{2} / \mathrm{ft}^{3}\right)$ [21]. Notably, the amount of $\mathrm{CO}_{2}$ emissions estimated from the energy used by the separation process is only $\sim 0.6 \mathrm{~kg} / 1 \mathrm{~kg}-\mathrm{CO}_{2}$ captured, leading to negative emission of $\mathrm{CO}_{2}$. These simple process simulation results encouraged us to explore more realistic membrane performances and process conditions for m-DAC. 
Table 1 The m-DAC separation process outcomes estimated by the process simulation

\begin{tabular}{|c|c|c|c|c|}
\hline Number of separation stages & 1 & 2 & 3 & 4 \\
\hline $\mathrm{CO}_{2}$ concentration in permeate $(\%)$ & 0.6 & 2.9 & 10.8 & 29.8 \\
\hline Membrane area $\left(\mathrm{m}^{2} / \mathrm{kg}-\mathrm{CO}_{2} /\right.$ day $)$ & 2.57 & 3.04 & 3.16 & 3.19 \\
\hline $\begin{array}{l}\text { Energy required for vacuuming }(\mathrm{kWh} / \mathrm{kg}- \\
\left.\mathrm{CO}_{2} / \text { day }\right)\end{array}$ & 12.7 & 15.1 & 15.8 & 16.0 \\
\hline $\begin{array}{l}\mathrm{CO}_{2} \text { emission related to the energy } \\
\text { production }\left(\mathrm{kgCO}_{2}{ }^{\text {emitted }} / \mathrm{kgCO}_{2}{ }^{\text {captured }}\right)^{\mathrm{a}}\end{array}$ & 0.48 & 0.57 & 0.59 & 0.6 \\
\hline
\end{tabular}

${ }^{a}$ The utilization of photovoltaic electricity (PV-e) considered for separation process, and the amount of $\mathrm{CO}_{2}$ emissions relevant to the required energy is calculated from the carbon intensity of PV-e in Japan $(0.038 \mathrm{~kg} / \mathrm{kWh})[33]$

\section{Key parameters in the $\mathrm{CO}_{2}$ separation by membranes}

In the membrane separation process, both membrane properties and process parameters play an important role in determining the overall performance of the process. In addition to the gas permeance and selectivity of membranes, stage cut and the pressure ratio between the feed and the permeate sides are important.

\section{Gas permeance}

The gas permeance property is important because the required membrane area is inversely proportional to this value. Therefore, only high permeance separation membranes can be considered as a practical option for DAC with realistic size and pressure conditions. It is noteworthy that membranes with high permeance would allow for the building of multistage separation processes with a reasonable membrane size, as shown in Table 1.

\section{$\mathrm{CO}_{2}$ selectivity of membranes}

The selectivity of membranes for $\mathrm{CO}_{2}$ capture is also critical. Single-step membrane separation can hardly exceed more than $1 \%$ of $400 \mathrm{ppm} \mathrm{CO}_{2}$ in air, even with a high $\mathrm{CO}_{2} /$ $\mathrm{N}_{2}$ selectivity of 70 . However, the high $\mathrm{CO}_{2}$ permeance of the membrane enables the application of multistage separation, making it feasible even with relatively low membrane selectivity for $\mathrm{CO}_{2}$ over other gas species. Figure $2 \mathrm{a}$ shows a three-stage membrane separation process used to analyze the effect of the $\mathrm{CO}_{2}$ selectivity on the $\mathrm{CO}_{2}$ purity in the product gas. The $\mathrm{CO}_{2}$ permeances of all membranes are assumed to be 10,000 GPU. The pressures of the feed and permeate sides at each separation step are 110 and $2 \mathrm{kPa}$, respectively. The $\mathrm{CO}_{2}$ selectivity of membranes over other gases is a variable parameter, but the same membrane performances at every stage are used for the analysis.
In this model, the membrane size was adjusted to maintain the $\mathrm{CO}_{2}$ concentration of $300 \mathrm{ppm}$ in the retentate of each stage. As seen in Fig. 2b, the final $\mathrm{CO}_{2}$ concentration does not exceed more than $10 \%$ when the $\mathrm{CO}_{2}$ selectivity is less than 20 , even after three-stage separation. Higher $\mathrm{CO}_{2}$ selectivity results in higher $\mathrm{CO}_{2}$ concentrations in the permeate gas. However, the enhancement of $\mathrm{CO}_{2}$ purity in the product becomes moderate for the selectivity of more than 30. The required power of the pump at the first stage is the largest, and subsequent separation stages consume less energy since the gas volume after the first stage is significantly reduced (Fig. 2c). Higher $\mathrm{CO}_{2}$ selectivity contributes to the reduction of the pump energy, although the reduction rate becomes lower at selectivities greater than 30 (the black diamonds in Fig. 2c).

These results clearly show that the $\mathrm{CO}_{2}$ selectivity over other gases has a definitive and critical impact on the performance of m-DAC.

\section{Pressure ratio}

Process conditions also play an important role in determining the process performance in addition to the intrinsic membrane properties. The pressure ratio $(\varphi)$, defined in Eq. (1), is a particularly important factor in the membrane separation process [22]

$\varphi=\frac{p_{f}}{p_{p}}$,

where $p_{f}$ and $p_{p}$ are the total pressure at the feed and permeate sides of the membrane. By considering the mass balances in a single membrane separation process, the partial pressure of $\mathrm{CO}_{2}$ in the permeate cannot exceed the partial pressure of $\mathrm{CO}_{2}$ in the feed; therefore, the following equation should be satisfied:

$p_{p} \times C_{p} \leq p_{f} \times C_{f}$,

where $C_{p}$ and $C_{f}$ are the mole fractions of $\mathrm{CO}_{2}$ at the permeate and feed side, respectively. Hence, the following relation defines the permeate concentration with feed concentration and pressure ratio:

$C_{p} \leq C_{f} \times \varphi$.

This equation implies that the pressure ratio limits the mole fraction of $\mathrm{CO}_{2}$ at the permeate side, independent of the membrane selectivity. Figure $3 \mathrm{a}$ shows the effect of the pressure ratio on the $\mathrm{CO}_{2}$ concentration at the permeate (product) and the retentate sides in the single-step separation from the air. The small pressure ratio has a large impact on the $\mathrm{CO}_{2}$ concentration in the permeate and retentate streams, but the trend plateaus in the high-pressure ratio 
(a)

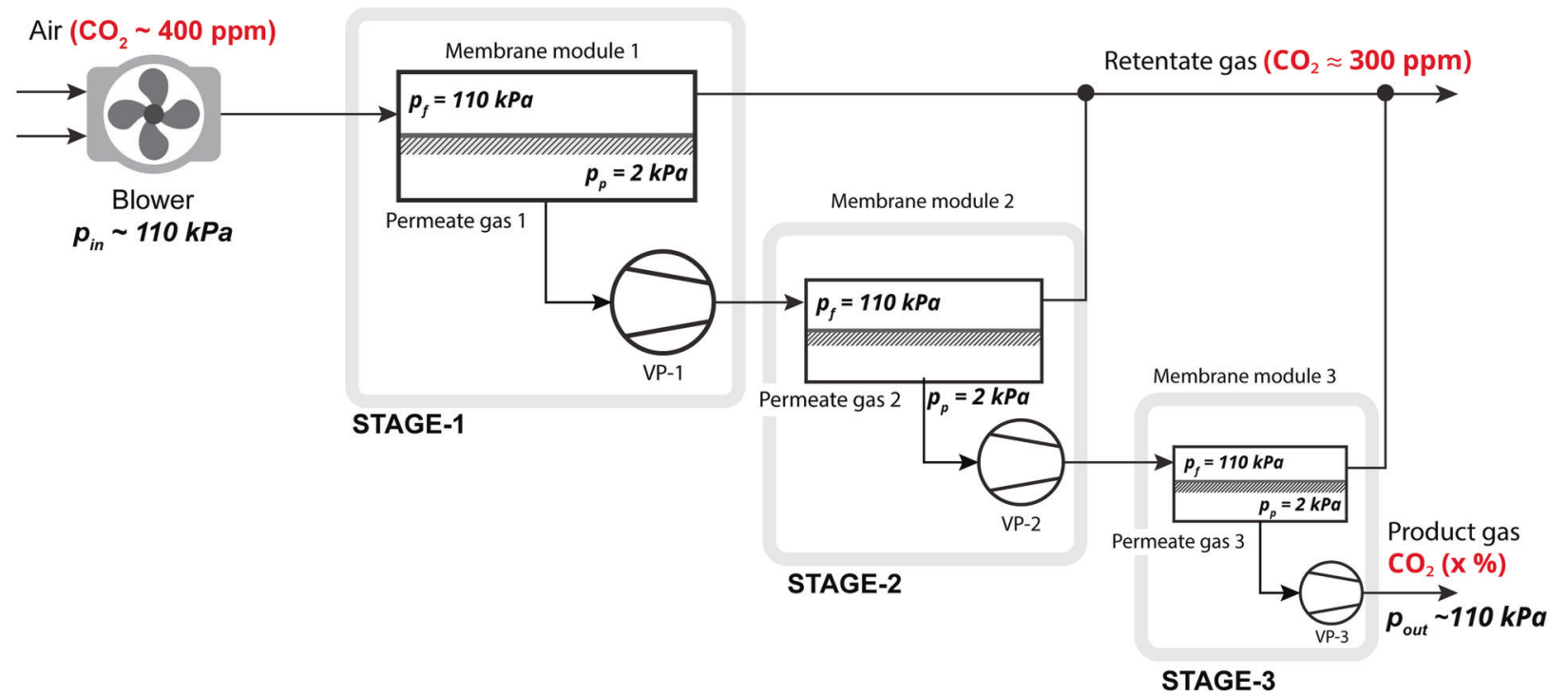

(b)

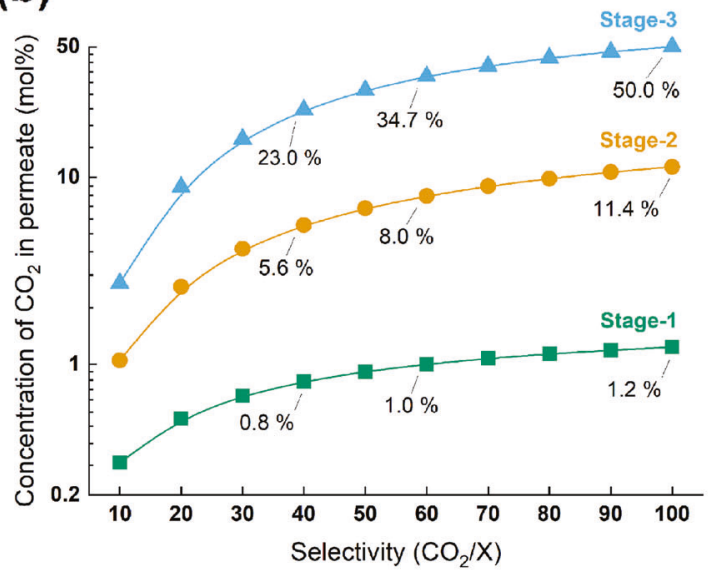

Fig. 2 a Scheme of the three-stage membrane process for $\mathrm{CO}_{2}$ separation from air. b Dependence of $\mathrm{CO}_{2}$ purity in the product stream on membrane selectivity. c Requirements for the vacuum pump power

region $(\varphi>30)$. This result demonstrates the importance of the pressure ratio in determining the $\mathrm{CO}_{2}$ concentrations after membrane separation. The pressure ratio is also related to the energy needed for vacuuming. Figure $3 \mathrm{~b}$ shows the required energy (per $\mathrm{kg}-\mathrm{CO}_{2}$ ), and there is an optimum pressure ratio for having local minimum energy at pressure ratios of $10-15$, which is similar to the optimum pressure ratio for postcombustion $\mathrm{CO}_{2}$ capture [15].

\section{Stage cut}

In membrane separation, the feed gas flows along the membrane surface, and the $\mathrm{CO}_{2}$ concentration gradually decreases since $\mathrm{CO}_{2}$ selectively permeates across a membrane, leading to a reduced driving force for permeation.

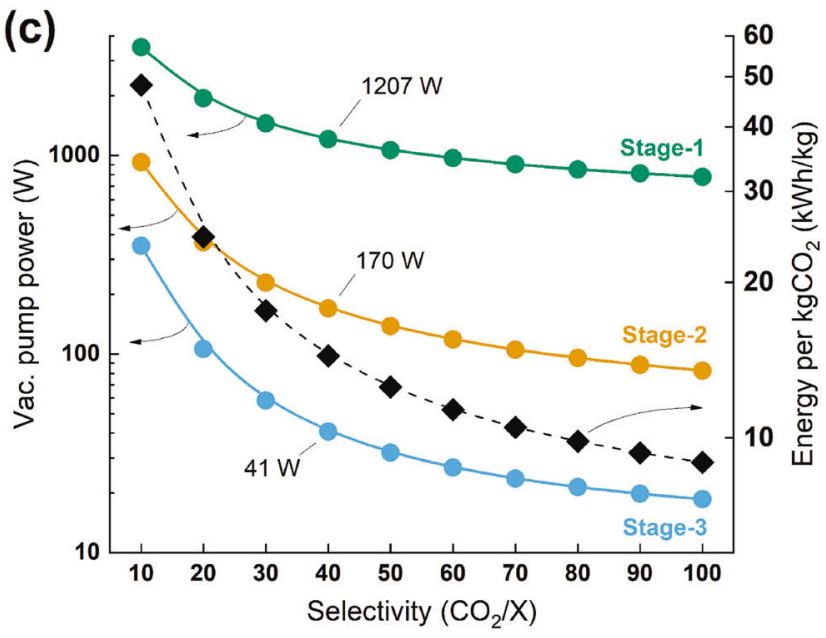

(circles) and total daily energy/per $\mathrm{kg}$ of $\mathrm{CO}_{2}$ (diamonds) depending on membrane selectivity (the setting for pressure ratio: $\varphi=50$ )

In contrast, the concentrations of other (less permeable) gases in the residue stream are relatively sustained, resulting in a stable driving force. Especially for high gas-permeable membranes, this effect becomes increasingly significant. A larger membrane area and slower feed flow allow for more efficient permeation of gas across a membrane. Therefore, the degree of separation has a trade-off relationship between purity and recovery that can be controlled by the flow rates and membrane area, which is known as the stage cut $(\theta)$, which is defined as the ratio of permeate to feed flow. Figure $3 \mathrm{c}$ shows the effect of stage cut on the $\mathrm{CO}_{2}$ concentration of the permeate and feed sides. In the region of a relatively small stage cut, a higher $\mathrm{CO}_{2}$ concentration at the permeate side is obtained. However, the portion of $\mathrm{CO}_{2}$ separated from the feed gas (recovery rate) inevitably decreases and vice 

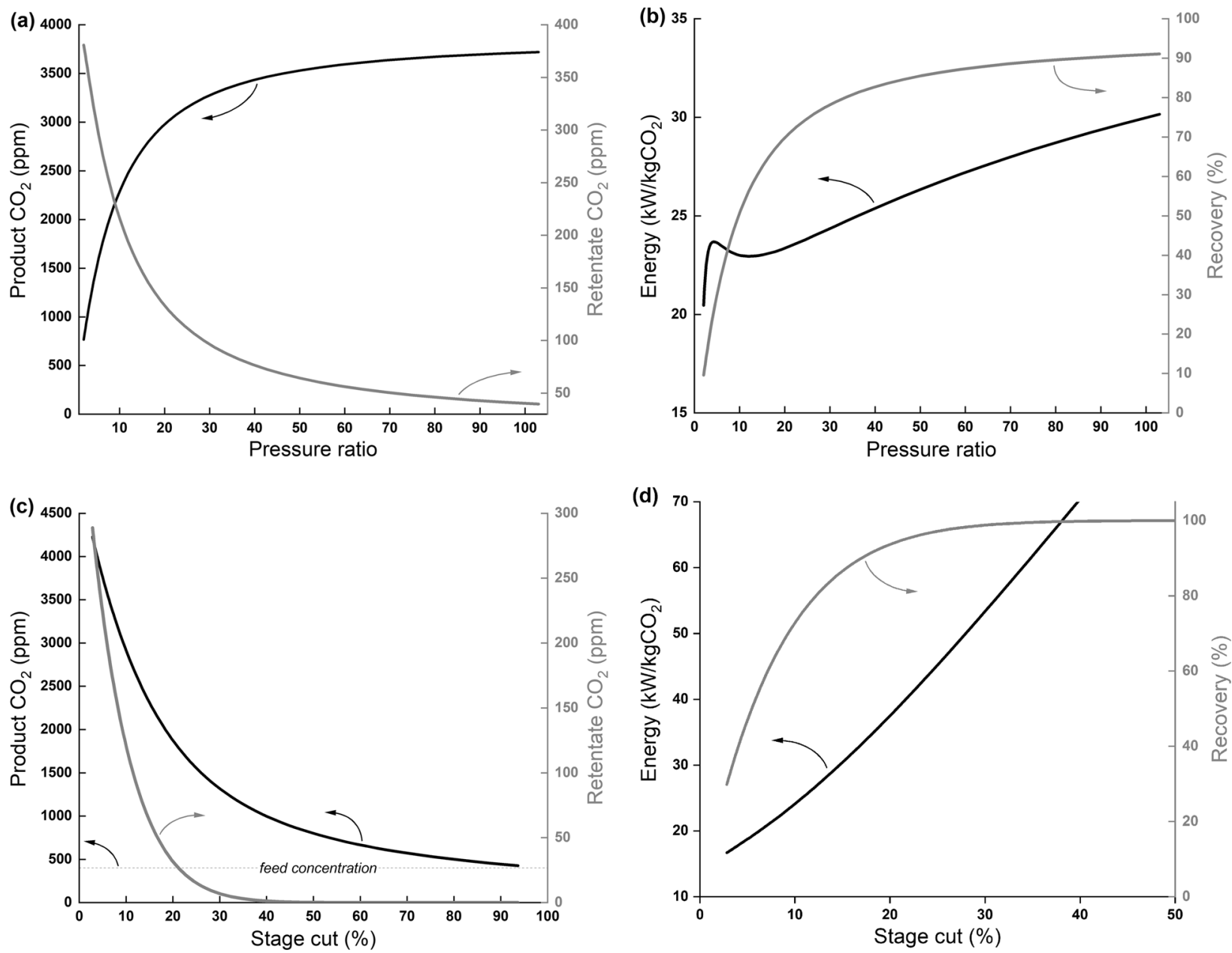

Fig. 3 Influence of the pressure ratio $\varphi$ and stage cut $(\theta)$ on the $\mathrm{CO}_{2}$ separation from the air using a $\mathrm{CO}_{2}$ selective membrane. a Dependence of $\mathrm{CO}_{2}$ concentration in permeate and retentate streams and $\mathbf{b}$ $\mathrm{CO}_{2}$-mass normalized daily energy requirements on pressure ratio (other parameters: stage cut $\theta \sim 5-10$ and selectivity $\mathrm{CO}_{2} / X=30$,

versa for relatively large stage cuts. Specifically, one can see that product purity and recovery of $\mathrm{CO}_{2}$ from air show a trade-off relationship (Fig. 3c, d). The stage cut factor can be controlled by the membrane area (at a stable feed flow) and should be optimized to achieve a target separation.

\section{The design strategy of $m-D A C$ and sensitivity analysis}

By considering the importance of the factors described above, the membrane process for DAC was investigated as follows.

\section{Target $\mathrm{CO}_{2}$ concentration for m-DAC}

$\mathrm{CO}_{2}$ capture is one component of the process of $\mathrm{CO}_{2}$ capture, utilization, and sequestration (CCUS). Thus, the target

where $X$ identifies other components of air $\left(\mathrm{N}_{2}, \mathrm{O}_{2}\right.$, Ar). c Dependence of $\mathrm{CO}_{2}$ concentration in permeate and retentate streams and $\mathbf{d} \mathrm{CO}_{2-}$ mass normalized daily energy requirements on stage cut (other parameters: pressure ratio, $\varphi=20$; selectivity $\mathrm{CO}_{2} / X=30$, where $X$ identifies other components of air $\left(\mathrm{N}_{2}, \mathrm{O}_{2}, \mathrm{Ar}\right)$

conditions for $\mathrm{CO}_{2}$ capture depend on the subsequent $\mathrm{CO}_{2}$ treatment process. For transport and geological sequestration, a nearly pure $\mathrm{CO}_{2}$ stream is required [23]. On the other hand, there are no specific concentration requirements for $\mathrm{CO}_{2}$ utilization. A high concentration of $\mathrm{CO}_{2}$ is certainly desirable in $\mathrm{CO}_{2}$ conversion reactions to value-added materials. However, high purity at the $\mathrm{CO}_{2}$ separation step is not necessary if subsequent conversion steps can still proceed efficiently. Indeed, Kim et al. showed the potential for electrochemical conversion of low-purity $\mathrm{CO}_{2}$ [24]. They used $\mathrm{CO}_{2}$ gas diluted with $\mathrm{N}_{2}$ as a feedstock for the electrochemical reduction of $\mathrm{CO}_{2}$ and achieved efficient conversion reactions to $\mathrm{CO}$, even at feed $\mathrm{CO}_{2}$ concentrations as low as $20 \%$. Kumagai et al. also achieved $\mathrm{CO}_{2}$ conversion even at only $1000 \mathrm{ppm} \mathrm{CO}_{2}$ [25]. These results make it apparent that it is not necessary to produce a highpurity $\mathrm{CO}_{2}$ stream by membrane separation. Based on these considerations, for the subsequent analysis, the target $\mathrm{CO}_{2}$ 
Table 2 The m-DAC separation outcomes with the pressure ratio of $25\left(p_{\text {perm }}=4 \mathrm{kPa}\right)$

\begin{tabular}{|c|c|c|c|c|c|}
\hline Separation stage & First & Second & Third & Fourth & total \\
\hline $\mathrm{CO}_{2}$ concentration in permeate $(\%)$ & 0.7 & 3.9 & 15.5 & 42.4 & - \\
\hline Membrane area $\left(\mathrm{m}^{2} / \mathrm{kg}-\mathrm{CO}_{2} /\right.$ day $)$ & 2.15 & 0.35 & 0.08 & 0.02 & 2.6 \\
\hline Energy required for vacuuming $\left(\mathrm{kWh} / \mathrm{kg}-\mathrm{CO}_{2} / \mathrm{day}\right)$ & 11.6 & 1.9 & 0.5 & 0.2 & 14.2 \\
\hline $\begin{array}{l}\mathrm{CO}_{2} \text { emission related to the energy production }\left(\mathrm{kgCO}_{2}{ }^{\text {emitted }}\right. \\
\left.\mathrm{kgCO}_{2}^{\text {captured }}\right)^{\mathrm{a}}\end{array}$ & 0.44 & 0.07 & 0.02 & 0.01 & 0.54 \\
\hline
\end{tabular}

${ }^{\mathrm{a}}$ The utilization of photovoltaic electricity (PV-e) considered for separation process, and the amount of $\mathrm{CO}_{2}$ emissions relevant to the required energy is calculated from the carbon intensity of PV-e in Japan $(0.038 \mathrm{~kg} /$ kWh) [33] purity in the final gas was set to $40 \%$, which is 1000 times its concentration in the air.

\section{Stage cut and pressure ratio}

The main purpose of DAC is to reduce the $\mathrm{CO}_{2}$ concentration in the air by removing historical emissions and to offset the emissions that are difficult to avoid. Generally, membrane separation emits a retentate gas to the external air. Therefore, the $\mathrm{CO}_{2}$ concentration of the retentate gas should be less than $300 \mathrm{ppm}$ (characteristic atmospheric $\mathrm{CO}_{2}$ concentration of the preindustrial period) by adjusting the stage cut (controlled by membrane area).

The pressure ratio also impacts the total performance of the DAC membranes. As shown in Fig. 3b, the pressure ratios ranging from $\sim 10$ to 20 , which is a local minimum of the consumed energy, would be reasonable for analysis. However, the final concentration of $\mathrm{CO}_{2}$ within this pressure ratio range cannot reach $40 \%$ even after four-stage separation. When the pressure at the permeate side is $4 \mathrm{kPa}$ $(\varphi=25)$, the final $\mathrm{CO}_{2}$ concentration can exceed $40 \%$ (Table 2). Although the final concentration of $\mathrm{CO}_{2}$ also depends on the membrane selectivity, as shown in Fig. 3a, pressure ratios higher than 30 in the membrane separation seem to be needed.

\section{Influence of the gas permeance and selectivity on the $\mathrm{m}$-DAC performance}

Once the concentration of retentate $\mathrm{CO}_{2}$ concentration is defined, the volume of the permeate gas is simultaneously determined according to mass-balance constraints. The size of a membrane with relatively high gas permeance becomes small and vice versa if the separation parameters are identical. Therefore, the high gas permeance contributes to the reduction of the required membrane size and allows for one to build relatively small modules for multistage separation with practical sizes.

Membrane selectivity to $\mathrm{CO}_{2}$ also plays an important role in building a feasible m-DAC process. As shown in Fig. 2, membranes with $\mathrm{CO}_{2}$ selectivity of more than 70 can achieve the target $\mathrm{CO}_{2}$ concentration of $40 \%$ with a pressure
Table 3 Effect of the $\mathrm{CO}_{2}$ selectivity on the performances of the fourstage m-DAC process (pressure ratio $\varphi \approx 50$ )

\begin{tabular}{lrrc}
\hline Selectivity $\left(\mathrm{CO}_{2} / X\right)^{\mathrm{a}}$ & \multicolumn{1}{c}{50} & \multicolumn{1}{c}{40} & 30 \\
\hline $\mathrm{CO}_{2}$ concentration in product $(\%)$ & 66.7 & \multicolumn{1}{c}{56.3} & 41.6 \\
Membrane area $\left(\mathrm{m}^{2} / \mathrm{kg}-\mathrm{CO}_{2} / \mathrm{day}\right)$ & 4.63 & 4.28 & 3.95 \\
$\begin{array}{l}\text { Energy required for vacuuming }\left(\mathrm{kWh} / \mathrm{kg}-\mathrm{CO}_{2} /\right. \\
\text { day) }\end{array}$ & 12.29 & 14.12 & 17.29 \\
$\mathrm{CO}_{2}$ emission related to the energy production & 0.47 & 0.54 & 0.66 \\
$\left(\mathrm{kgCO}_{2}{ }^{\left.\text {emitted } / \mathrm{kgCO}_{2}{ }^{\text {captured }}\right)^{\mathrm{b}}}\right.$ & & &
\end{tabular}

${ }^{\mathrm{a}} X=\mathrm{N}_{2}, \mathrm{O}_{2}$, and $\mathrm{Ar}$

${ }^{\mathrm{b}}$ The utilization of photovoltaic electricity (PV-e) considered for separation process, and the amount of $\mathrm{CO}_{2}$ emissions relevant to the required energy is calculated from the carbon intensity of PV-e in Japan $(0.038 \mathrm{~kg} / \mathrm{kWh})$ [33]

ratio of 22 (in the three-stage process). However, the total performance of m-DAC depends on the parameters described above, and there may be a window of $\mathrm{CO}_{2}$ selectivity to satisfy the current target (1000 times $\mathrm{CO}_{2}$ concentration). To explore the range of $\mathrm{CO}_{2}$ selectivity, the following conditions were considered.

(1) The pressures at the feed and permeate sides are 110 and $2 \mathrm{kPa}$, respectively $(\varphi=55)$.

(2) The $\mathrm{CO}_{2}$ concentration of the retentate gas is set to 300 ppm.

(3) Four-stage separation is considered (similar to Fig. 1).

(4) The $\mathrm{CO}_{2}$ permeance is $10,000 \mathrm{GPU}$.

(5) The $\mathrm{CO}_{2}$ selectivities over $\mathrm{N}_{2}, \mathrm{O}_{2}$, and $\mathrm{Ar}$ are assumed to be identical.

The obtained results are standardized for capturing $1 \mathrm{~kg}$ of $\mathrm{CO}_{2}$ per day.

As summarized in Table 3, membrane separation with a relatively realistic $\mathrm{CO}_{2}$ selectivity of 30 can reach the target $\mathrm{CO}_{2}$ concentration (more than $40 \%$ ). The total amount of $\mathrm{CO}_{2}$ emissions through this process is less than $1 \mathrm{~kg}$, leading to negative emission of $\mathrm{CO}_{2}$ with a membrane size of less than $5 \mathrm{~m}^{2} / \mathrm{kg}-\mathrm{CO}_{2} /$ day. In the separation with relatively low selectivity, other gases also permeate faster, resulting in a rapid increase in the $\mathrm{CO}_{2}$ concentration of the 
retentate stream. Thus, the area of the membrane with lower selectivity should be smaller than that with higher selectivity to release the retentate gas with a $\mathrm{CO}_{2}$ concentration of less than $300 \mathrm{ppm}$. Highly $\mathrm{CO}_{2}$ selective membranes show relatively lower energy for vacuuming and $\mathrm{CO}_{2}$ emission through the DAC process.

These analyses imply that there is space to achieve the current target, 1000-fold preconcentration of the $\mathrm{CO}_{2}$ from air, by optimizing parameters, which has never been considered before. As a short summary, the membrane performances and process factors need to satisfy the following conditions:

(1) $\mathrm{CO}_{2}$ permeance: more than $10,000 \mathrm{GPU}$ to achieve realistic membrane sizes.

(2) $\mathrm{CO}_{2}$ selectivity $>30$ (higher selectivity is preferred).

(3) A pressure ratio $>30$ (a higher pressure ratio is preferred).

One can claim that the discussion of $\mathrm{CO}_{2}$ capture in $\mathrm{kg}$ mass range may be negligible to reduce the $\mathrm{CO}_{2}$ concentration in the air since the amount of already emitted $\mathrm{CO}_{2}$ is incredibly large. However, once we have such membranes, they can be considered for relatively large $\mathrm{CO}_{2}$ capture facilities. For example, the required membrane for one ton of $\mathrm{CO}_{2}$ capture per day is estimated to be less than $5000 \mathrm{~m}^{2}$, leading to less than $15.2 \mathrm{~m}^{3}(\sim 2.5 \mathrm{~m} \times 2.5 \mathrm{~m} \times$ $2.5 \mathrm{~m}$ in size) for the volume of the membrane unit. The massive installation of such membrane separation units would therefore have the potential to reduce the $\mathrm{CO}_{2}$ concentration in the air meaningfully.

In the present analysis, the electricity generated by the photovoltaic system was considered for m-DAC operation and to estimate the amount of $\mathrm{CO}_{2}$ emissions through the process. The price of PV electricity was $\$ 0.068 / \mathrm{kWh}$ in 2019 and predicted to average $\$ 0.039 / \mathrm{kWh}$ in 2021 [26], meaning that the cost of m-DAC can also be expected to fit within the socially acceptable price range. This paper aimed to evaluate the technical aspects of m-DAC and exploring the required membrane performances, and the analysis of the cost performance was not the main purpose. In addition, a large number of scenarios concerning electricity should be considered for detailed techno-economic analysis, including not only operational expenses but also capital expenses. Therefore, we did not examine the cost aspect of m-DAC in this paper. The reported estimates of cost (energy) of other DAC technologies vary from 50 to $1000 \$ / \mathrm{t}-\mathrm{CO}_{2}$, and the most detailed report describes the DAC process used by Carbon Engineering Ltd. (CE) relying on $\mathrm{CO}_{2}$ capture by strong bases $(\mathrm{KOH})$ interacting with air through the plastic contactor. The levelized cost of $\mathrm{CO}_{2}$ capture from 94 to 232 $\$ / \mathrm{t}-\mathrm{CO}_{2}$ was reported and was strongly dependent on financial assumptions and energy cost [13]. The CE design required $8.81 \mathrm{GJ}$ of natural gas or $5.25 \mathrm{GJ}$ of gas and 366 $\mathrm{kWhr}$ of electricity per $\mathrm{t}-\mathrm{CO}_{2}$. Earlier studies of similar processes provided costlier estimates, namely, 610 and 780 $\$ / \mathrm{t}-\mathrm{CO}_{2}$ in optimistic and realistic scenarios, respectively, [5]. Another recent report provided an estimate of the energies required in solid adsorbent-based DAC varying from ca. 15 to $60 \mathrm{MJ} / \mathrm{kg}-\mathrm{CO}_{2}\left(4.5-17 \mathrm{kWhr} / \mathrm{kg}-\mathrm{CO}_{2}\right)$ [12], and these energy requirements are similar to those described here for m-DAC.

\section{Concluding remarks}

In general, the DAC process has been considered in form of large-scale systems to process a vast amount of air efficiently. Although there is no question about deploying large and integrated systems for reducing the $\mathrm{CO}_{2}$ concentration in the air, expensive initial costs and specific site conditions for the plant installation limit the rapid and massive deployment of DAC systems. To meet the recommendation from the IPCC for achieving the $1.5^{\circ} \mathrm{C}$ scenario, other approaches should be proposed as much as possible. In this context, membrane separation has several advantages compared to the conventional sorbent-based DAC process. Generally, membrane separation is considered the most energy-efficient technique for $\mathrm{CO}_{2}$ separation among the various separation technologies. Moreover, this approach does not require special chemicals or sorbents for $\mathrm{CO}_{2}$ capture. The greatest advantage is that membrane separation systems are scalable and can be installed in a variety of locations. These characteristics of membrane separation can enable m-DAC to be the most suitable technology for ubiquitous and ambient DAC. This uniqueness of m-DAC provides opportunities to capture $\mathrm{CO}_{2}$ that have never been considered before. For example, the $\mathrm{CO}_{2}$ concentration in the school classroom often exceeds more than $1000 \mathrm{ppm}$ without ventilation since human beings emit $\mathrm{CO}_{2}$ at a rate of $\sim 1 \mathrm{~kg}$ per person per day [27]. In such places of higher $\mathrm{CO}_{2}$ concentrations, $\mathrm{CO}_{2}$ capture by membranes becomes relatively efficient since the driving force of $\mathrm{CO}_{2}$ is larger. Recently, Dittmeyer et al. discussed the potential of an air conditioner system with a $\mathrm{CO}_{2}$ capture function [28]. Their argument is based on existing DAC technologies that use $\mathrm{CO}_{2}$ absorption and adsorption. The energy cost of $\mathrm{CO}_{2}$ recovery is still high and it is essentially identical to the large-scale system, and specific chemicals for $\mathrm{CO}_{2}$ capture are required. This situation makes it difficult to introduce conventional systems into offices and private residences. Therefore, for a truly distributed and scalable DAC system, m-DAC would be the most suitable technology.

As discussed above, the permeance of $\mathrm{CO}_{2}$ and selectivity toward other gases $\left(\mathrm{N}_{2}, \mathrm{O}_{2}\right)$ together with the process parameters (pressure ratio and stage cut) will define the 


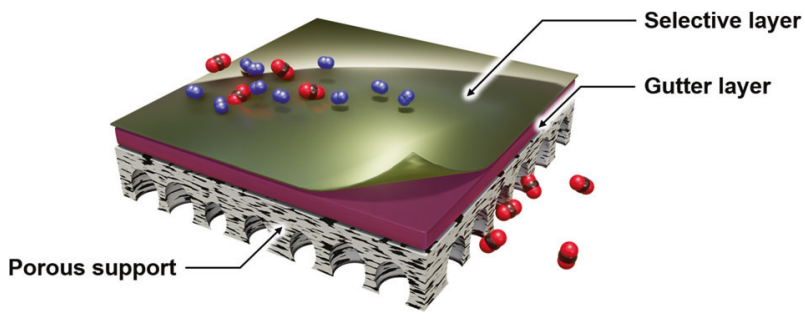

Fig. 4 Schematic illustration of a thin-film composite membrane

degree of preconcentration and required energy in the $\mathrm{m}$ DAC system. Membrane materials play a large role in capital investments, as the required membrane areas are relatively large. Therefore, the materials used should be suitable for thin-film fabrication. Considering the specific materials, thermally reversed polymers and polymers of intrinsic microporosity (PIMs) have shown superior $\mathrm{CO}_{2}$ permeability, breaking the upper bound [29], but higher $\mathrm{CO}_{2}$ selectivity is desired. Moreover, PIMs manifest accelerated physical aging when fabricated as submicronthick membranes [30]. By combining specific fillers and polymers, mixed-matrix membranes (MMMs) can reach both high $\mathrm{CO}_{2}$ permeability and selectivity. However, for the m-DAC process to be practical, the permeance is the key parameter (not permeability), which leads to the requirement of $\sim 100 \mathrm{~nm}$ membrane thicknesses. Most MMMs cannot be fabricated at this thickness. Facilitated transport membranes are promising, especially for the first step of separation with a low concentration of $\mathrm{CO}_{2}$ in the feed, but may lack performance in later stages where the $\mathrm{CO}_{2}$ concentration is higher.

Although the target properties of membranes for m-DAC are challenging, recently, a thin-film composite membrane approach was used to improve the performance [30, 31]. In this approach, the $\mathrm{CO}_{2}$ selective thin layer is deposited on the highly gas-permeable support layer, the so-called gutter layer, and assembled on a porous support (Fig. 4). We believe it is promising to provide membranes for m-DAC because the layers are often made of versatile, low-cost polymers that can be fabricated with thicknesses of a few tens of nanometers without losing the performance [18], while the selectivity can be improved by surface modification [19]. Moreover, for m-DAC, it is important to study all materials that show promising bulk performance in the form of thin membranes or thin composites to determine whether the separation is influenced by the thickness and whether large-scale, mechanically stable membranes can be fabricated.

In addition, $\mathrm{CO}_{2} / \mathrm{O}_{2}$ separation becomes important, especially for the $\mathrm{CO}_{2}$ conversion process, since oxygen prevents efficient $\mathrm{CO}_{2}$ reduction [32]. To the best of our knowledge, $\mathrm{CO}_{2} / \mathrm{O}_{2}$ separation by membranes has rarely been addressed in the literature, and most previous research on membrane-based $\mathrm{CO}_{2}$ separation was devoted to postcombustion capture (separation of $\mathrm{CO}_{2}$ and $\mathrm{N}_{2}$ ), precombustion capture $\left(\mathrm{CO}_{2}\right.$ and $\left.\mathrm{H}_{2}\right)$, and natural gas sweetening $\left(\mathrm{CO}_{2}\right.$ and $\left.\mathrm{CH}_{4}\right)$. Although much research is related to oxygen-enriching membranes, for example, that based on oxygen ion conductive materials, silicone-based polymers, or other organic polymers, most of the studies focus on $\mathrm{O}_{2}$ separation over $\mathrm{N}_{2}$ and do not report preferential $\mathrm{CO}_{2}$ permeation over $\mathrm{O}_{2}$. All $\mathrm{CO}_{2}$ capture technologies, including this m-DAC process, should be combined with successive processes to manage captured $\mathrm{CO}_{2}$. Chemical conversion is one of the major processes to circulate $\mathrm{CO}_{2}$ as a carbon source. In the process of $\mathrm{CO}_{2}$ conversion, it is chemically reduced to other value-added compounds, such as $\mathrm{CO}$ and $\mathrm{CH}_{4} \cdot \mathrm{O}_{2}$ inhibits the conversion of $\mathrm{CO}_{2}$ to the corresponding reduced form since it is a strong oxidant. Therefore, the product gas from the m-DAC system should not only achieve a relevant concentration of $\mathrm{CO}_{2}$ but also significantly reduce concentrations of $\mathrm{O}_{2}$, which emphasize the requirement of high $\mathrm{CO}_{2} / \mathrm{O}_{2}$ selectivity, in addition to $\mathrm{CO}_{2} / \mathrm{N}_{2}$ selectivity, although such a separation situation has never been considered.

As described above, the $\mathrm{CO}_{2}$ capture process is one component of CCUS and thus the subsequent process after DAC by membranes should be considered carefully. The target performance of the membrane for DAC depends on the requirements in the subsequent utilization processes. The simplicity of membrane separation offers many opportunities to capture and utilize $\mathrm{CO}_{2}$, and this versatile ability of the m-DAC process has great potential to establish a future sustainable and circular economy enabled by carbon recycling and negative carbon emissions.

Acknowledgements This work was supported by the World Premier International Research Center Initiative (WPI), sponsored by the Japanese Ministry of Education, Culture, Sports, Science, and Technology. SF acknowledges the Japan Society for Promotion of Science (JSPS) for a Grant-in-Aid for Scientific Research (B) (JSPS KAKENHI Grant Number JP20H02781). RS acknowledges the Japan Society for Promotion of Science (JSPS) for a Grant-in-Aid for Early Career Scientists (JSPS KAKENHI Grant Number JP19K15342).

\section{Compliance with ethical standards}

Conflict of interest The authors declare that they have no conflict of interest.

Publisher's note Springer Nature remains neutral with regard to jurisdictional claims in published maps and institutional affiliations.

Open Access This article is licensed under a Creative Commons Attribution 4.0 International License, which permits use, sharing, adaptation, distribution and reproduction in any medium or format, as long as you give appropriate credit to the original author(s) and the source, provide a link to the Creative Commons license, and indicate if changes were made. The images or other third party material in this 
article are included in the article's Creative Commons license, unless indicated otherwise in a credit line to the material. If material is not included in the article's Creative Commons license and your intended use is not permitted by statutory regulation or exceeds the permitted use, you will need to obtain permission directly from the copyright holder. To view a copy of this license, visit http://creativecommons. org/licenses/by/4.0/.

\section{References}

1. Masson-Delmotte V, Zhai P, Pörtner H-O, Roberts D, Skea J, Shukla PR, et al. Summary for Policymakers. In: Global warming of $1.5^{\circ} \mathrm{C}$. An IPCC special report on the impacts of global warming of $1.5^{\circ} \mathrm{C}$ above pre-industrial levels and related global greenhouse gas emission pathways, in the context of strengthening the global response to the threat of climate change, sustainable development, and efforts to eradicate poverty. IPCC; 2018. https:// report.ipcc.ch/sr15/pdf/sr15_spm_final.pdf.

2. Kriegler E, Luderer G, Bauer N, Baumstark L, Fujimori S, Popp A, et al. Pathways limiting warming to $1.5^{\circ} \mathrm{C}$ : a tale of turning around in no time? Philos Trans R Soc A Math Phys Eng Sci. 2018:376:20160457.

3. Fuss S, Canadell JG, Peters GP, Tavoni M, Andrew RM, Ciais P, et al. Betting on negative emissions. Nat Clim Change. 2014;4:850-3.

4. Gasser T, Guivarch C, Tachiiri K, Jones CD, Ciais P. Negative emissions physically needed to keep global warming below $2{ }^{\circ} \mathrm{C}$. Nat Commun. 2015;6:7958.

5. Socolow R, Desmond M, Aines R, Blackstock J, Bolland O, Kaarsberg T, et al. Direct air capture of $\mathrm{CO}_{2}$ with chemicals panel on public affairs. Am Phys Soc. 2011;100:1-91.

6. Sanz-Pérez ES, Murdock CR, Didas SA, Jones CW. Direct capture of $\mathrm{CO}_{2}$ from ambient air. Chem Rev. 2016;116:11840-76.

7. Keith DW. Why capture $\mathrm{CO}_{2}$ from the atmosphere? Science. 2009;325:1654-5.

8. National Academies of Sciences, Engineering, and Medicine. Negative Emissions Technologies and Reliable Sequestration: A Research Agenda. Washington, DC: The National Academies Press; 2019. https://doi.org/10.17226/25259.

9. Smith P, Davis SJ, Creutzig F, Fuss S, Minx J, Gabrielle B, et al. Biophysical and economic limits to negative $\mathrm{CO}_{2}$ emissions. Nat Clim Change. 2016;6:42-50.

10. Minx JC, Lamb WF, Callaghan MW, Fuss S, Hilaire J, Creutzig F, et al. Negative emissions-part 1: research landscape and synthesis. Environ Res Lett. 2018;13:063001.

11. Fuss S, Lamb WF, Callaghan MW, Hilaire J, Creutzig F, Amann $\mathrm{T}$, et al. Negative emissions-part 2: costs, potentials and side effects. Environ Res Lett. 2018;13:063002.

12. Stampi-Bombelli V, van der Spek M, Mazzotti M. Analysis of direct capture of $\mathrm{CO}_{2}$ from ambient air via steam-assisted temperature-vacuum swing adsorption. Adsorption. 2020. https://doi.org/10.1007/s10450-020-00249-w.

13. Keith DW, Holmes G, St. Angelo D, Heidel K. A process for capturing $\mathrm{CO}_{2}$ from the atmosphere. Joule. 2018;2:1573-94.

14. Baker RW, Freeman B, Kniep J, Huang YI, Merkel TC. $\mathrm{CO}_{2}$ capture from cement plants and steel mills using membranes. Ind Eng Chem Res. 2018;57:15963-70.

15. Merkel TC, Lin H, Wei X, Baker RW. Power plant postcombustion carbon dioxide capture: an opportunity for membranes. J Memb Sci. 2010;359:126-39.
16. Keith DW, Heidel K, Cherry R. In: Brian L, editor. Geoengineering climate change. Environment necessity or Pandora's box? Capturing $\mathrm{CO}_{2}$ from atmosphere: rationale and process design considerations. (Chapter 6). Cambridge University Press; 2010. p. 107-26.

17. Yoo MJ, Kim KH, Lee JH, Kim TW, Chung CW, Cho YH, et al. Ultrathin gutter layer for high-performance thin-film composite membranes for $\mathrm{CO}_{2}$ separation. J Memb Sci. 2018;566:336-45.

18. Fujikawa S, Ariyoshi M, Selyanchyn R, Kunitake T. Ultra-fast, selective $\mathrm{CO}_{2}$ permeation by free-standing siloxane nanomembranes. Chem Lett. 2019;48:1351-4.

19. Selyanchyn O, Selyanchyn R, Fujikawa S. Critical role of the molecular interface in double-layered Pebax-1657/PDMS nanomembranes for highly efficient $\mathrm{CO}_{2} / \mathrm{N}_{2}$ gas separation. ACS Appl Mater Interfaces. 2020;12:33196-209.

20. Bounaceur R, Berger E, Pfister M, Ramirez Santos AA, Favre E. Rigorous variable permeability modelling and process simulation for the design of polymeric membrane gas separation units: MEMSIC simulation tool. J Memb Sci. 2017;523:77-91.

21. Li D, Wang R, Chung T-S. Fabrication of lab-scale hollow fiber membrane modules with high packing density. Sep Purif Technol. 2004;40:15-30.

22. Huang Y, Merkel TC, Baker RW. Pressure ratio and its impact on membrane gas separation processes. J Memb Sci. 2014;463:33-40.

23. IPCC. IPCC special report on carbon dioxide capture and storage. Metz B, Davidson O, de Coninck HC, Loos M, Meyer LA, editors. Prepared by Working Group III of the Intergovernmental Panel on Climate Change. Cambridge, UK: Cambridge University Press. p. 442.

24. Kim B, Ma S, Molly Jhong H-R, Kenis PJA. Influence of dilute feed and $\mathrm{pH}$ on electrochemical reduction of $\mathrm{CO}_{2}$ to $\mathrm{CO}$ on $\mathrm{Ag}$ in a continuous flow electrolyzer. Electrochim Acta. 2015;166:271-6.

25. Kumagai H, Nishikawa T, Koizumi H, Yatsu T, Sahara G, Yamazaki Y, et al. Electrocatalytic reduction of low concentration CO2. Chem Sci. 2019;10:1597-606.

26. IRENA. Renewable power generation costs in 2019. IRENA; 2020. https://www.irena.org/-/media/Files/IRENA/Agency/ Publication/2020/Jun/IRENA_Power_Generation_Costs_2019. pdf.

27. Ranjan M, Herzog HJ. Feasibility of air capture. Energy Procedia. 2011;4:2869-76.

28. Dittmeyer R, Klumpp M, Kant P, Ozin GA. Crowd oil not crude oil. Nat Commun. 2019;10:1818.

29. Comesaña-Gándara B, Chen J, Bezzu CG, Carta M, Rose I, Ferrari MC, et al. Redefining the Robeson upper bounds for $\mathrm{CO}_{2} /$ $\mathrm{CH}_{4}$ and $\mathrm{CO}_{2} / \mathrm{N}_{2}$ separations using a series of ultrapermeable benzotriptycene-based polymers of intrinsic microporosity. Energy Environ Sci. 2019;12:2733-40.

30. Selyanchyn R, Fujikawa S. Membrane thinning for efficient $\mathrm{CO}_{2}$ capture. Sci Technol Adv Mater. 2017;18:816-27.

31. Xie K, Fu Q, Qiao GG, Webley PA. Recent progress on fabrication methods of polymeric thin film gas separation membranes for $\mathrm{CO}_{2}$ capture. J Memb Sci. 2019;572:38-60.

32. Williams K, Corbin N, Zeng J, Lazouski N, Yang DT, Manthiram K. Protecting effect of mass transport during electrochemical reduction of oxygenated carbon dioxide feedstocks. Sustain Energy Fuels. 2019;3:1225-32.

33. Federation of Electric Power Companies of Japan. Energy and Environment 2016. Federation of Electric Power Companies of Japan; 2017. https://www.fepc.or.jp/english/library/energy_ environment/_icsFiles/afieldfile/2017/12/11/env_ene2016e.pdf. 